\title{
A Case of Livedoid Vasculopathy Successfully Treated with Sulodexide
}

\author{
Chang Hwa Song ${ }^{1}$, Dong Seok Shin ${ }^{1}$, Ju Wang Jang, Tae Lim Kim, Young Gyun Kim, Joung Soo Kim, \\ Hyun-Min Seo
}

Department of Dermatology, Hanyang University Guri Hospital, Guri, ${ }^{1}$ Department of Dermatology, Hanyang University Hospital, Seoul, Korea

We report a 29-year-old female with a one-month history of non-healing multiple erythematous to violaceous plaques with crusts over both legs and feet. Tender, scarring ulcers with surrounding erythema were present. The clinical manifestation, together with histopathologic findings of fibrinoid plugs within vascular lumens and walls, as well as red blood cell extravasation, led to diagnosis of livedoid vasculopathy. The patient experienced recurrent painful violaceous plaques with ulcerations during the two years of treatment with oral pentoxifylline $400 \mathrm{mg}$ three times daily. The cutaneous lesions and symptoms dramatically improved after the treatment regimen changed to oral sulodexide (250 lipasemic units) three times daily. Sulodexide, a highly purified mixture of glycosaminoglycans including dermatan sulfate and lowmolecular weight heparin, could be an effective therapy for recalcitrant livedoid vasculopathy. Herein, we report a case of livedoid vasculopathy treated with sulodexide, which has not previously been reported. (Ann Dermatol 32(6) $508 \sim 511$, 2020)

\section{-Keywords-}

Anticoagulants, Heparinoids, Livedoid, Sulodexide, Vasculo-

Received September 4, 2019, Revised October 10, 2019, Accepted for publication October 16, 2019

Corresponding author: Hyun-Min Seo, Department of Dermatology, Hanyang University Guri Hospital, 153 Gyeongchun-ro, Guri 11923, Korea. Tel: 8231-560-2284, Fax: 82-31-557-4872, E-mail: blackshm@nate.com ORCID: https://orcid.org/0000-0002-6897-494X

This is an Open Access article distributed under the terms of the Creative Commons Attribution Non-Commercial License (http://creativecommons. org/licenses/by-nc/4.0) which permits unrestricted non-commercial use, distribution, and reproduction in any medium, provided the original work is properly cited.

Copyright (c) The Korean Dermatological Association and The Korean Society for Investigative Dermatology pathy

\section{INTRODUCTION}

Livedoid vasculopathy (LV), also known as livedo vasculitis or livedoid vasculitis, is an orphan thrombotic skin disease characterized by recurrent painful ulcers and reddish-blue to purple net-like indurations called livedo racemosa $^{1,2}$. It precedes small, painful erythematous to purpuric ulcerative lesions, and healing results in sclerotic pale areas $^{3}$. LV shows recurrent episodic exacerbations and seasonal variation, including worsening of lesions in summ$\mathrm{er}^{2}$.

Although the exact pathogenesis remains unclear, LV is likely caused by increased prothrombotic and coagulation pathway activation. According to this etiology, anticoagulants including heparin, warfarin, and rivaroxaban are the most commonly reported monotherapies ${ }^{3}$. However, sulodexide, a heparinoid agent composed of low-molecular weight heparin $(80 \%)$ and dermatan sulfate $(20 \%)$, had not been applied for LV treatment ${ }^{4}$. Herein, we report a case of LV treated with the oral heparinoid sulodexide.

\section{CASE REPORT}

A 29-year-old female presented with livedo racemosa characterized by multiple erythematous to violaceous patches and plaques with crusts on both legs and feet (Fig. 1). The lesions had gradually started one month prior with tender, non-scarring ulcerative lesions and crusts. The patient has no underlying disease involving coagulation impairment and no medication history. Punch biopsy was performed at an erythematous plaque with a central viola- 

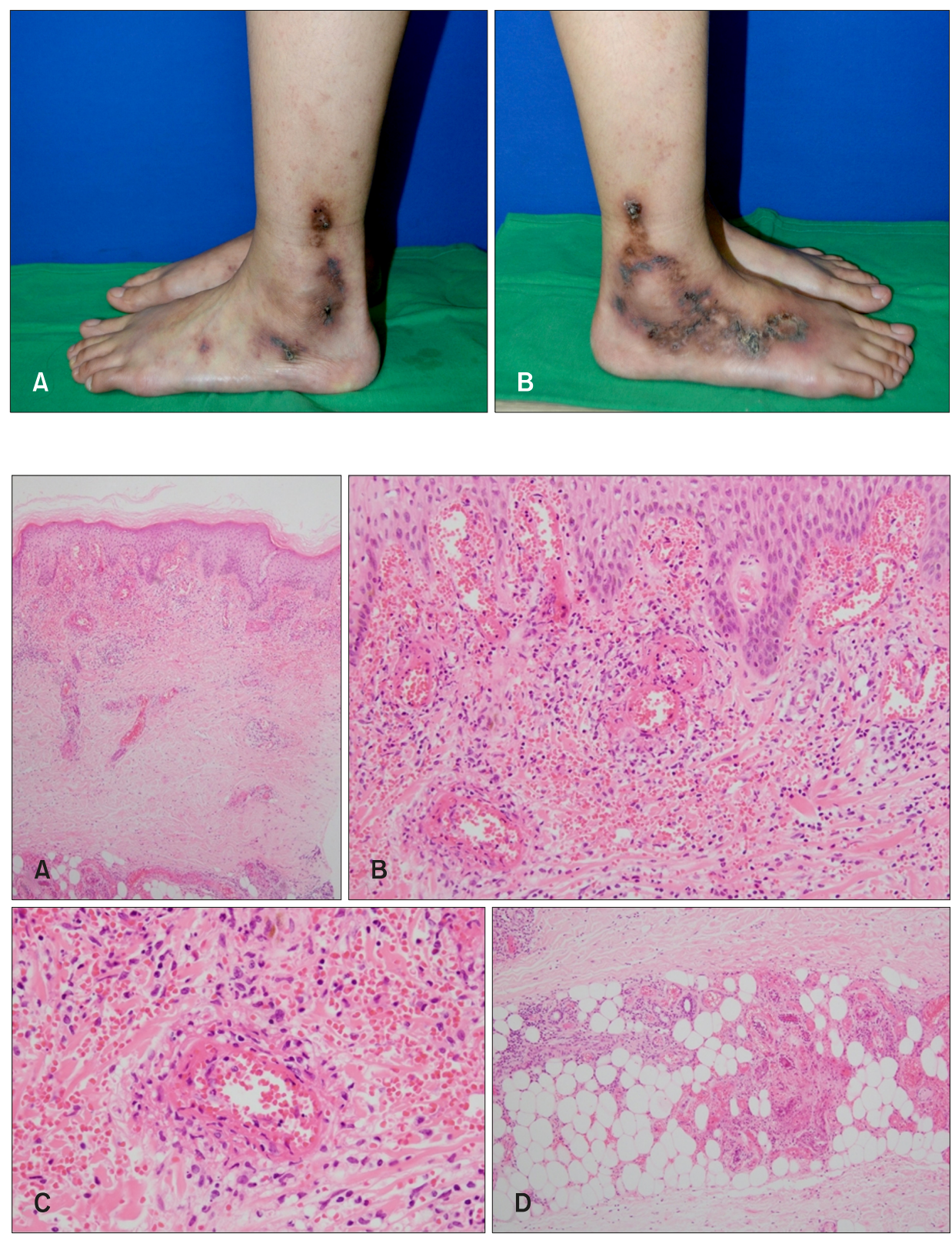

Fig. 2. Histopathologic findings. (A) Proliferation and dilatation of multiple capillaries in the papillary dermis $(\mathrm{H} \& \mathrm{E}, \times 1.25)(\mathrm{B})$ with red blood cell extravasation and hemosiderin deposition $(\mathrm{H} \& \mathrm{E}, \times 100)$. (C) Intraluminal fibrin deposition and thickened vascular walls containing fibrin with red blood cell extravasation and perivascular lymphocytic infiltration (H\&E, $\times 400)$. (D) Panniculitis featuring vascular proliferation and perivascular lymphocytic infiltration in the reticular dermis $(H \& E, \times 40)$. ceous patch on the lateral aspect of the right foot. The deep skin biopsy specimen showed proliferation of dermal vessels with red blood cell extravasation and hemosiderin pigment (Fig. 2). At higher magnification, vascular structures in the mid-dermis were occluded by intraluminal fibrin plugging, i.e., deposition of fibrin materials in the walls. Notably, there was no detectable leukocytoclastic vasculitis around the vessels, though moderate perivascular lymphocytic infiltration was observed. Based on the clinical and histopathologic findings, an LV diagnosis was made. Initially, the skin lesions responded well to oral pentoxifylline $400 \mathrm{mg}$ three times daily, topical mometasone furoate, and additional intralesional triamcinolone injection $(2.5 \mathrm{mg} / \mathrm{ml})$ every month. However, the patient suffered
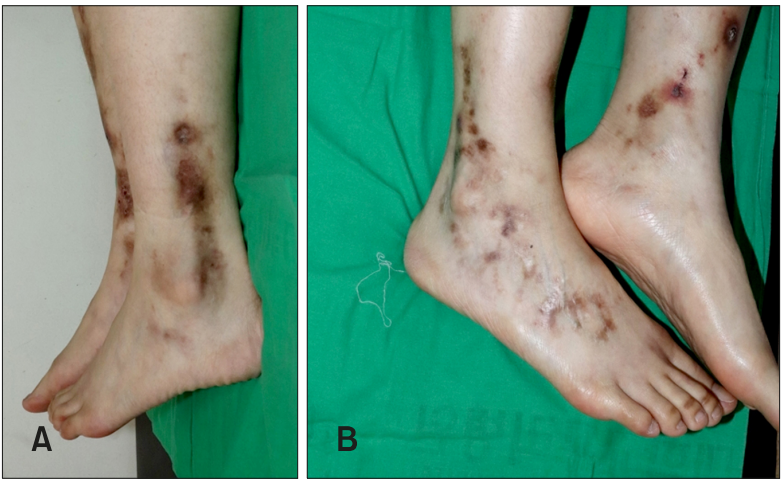

Fig. 3. (A, B) Treatment with oral sulodexide 250 lipasemic units three times daily over two months improved skin lesions, which became localized hyperpigmented patches with central crusts. 


\begin{tabular}{|c|c|c|c|c|}
\hline $\begin{array}{l}\text { First diagnosed: } \\
2 \text { years ago }\end{array}$ & $\begin{array}{l}\text { Recurrent tender, } \\
\text { erythematous to } \\
\text { violaceous plaques } \\
\text { with scarring ulcer }\end{array}$ & $\begin{array}{l}\text { Slightly improved } \\
\text { but persisted } \\
\text { skin lesions } \\
\text { and symptoms }\end{array}$ & $\begin{array}{l}\text { Skin lesions and } \\
\text { symptoms were } \\
\text { significantly } \\
\text { diminished }\end{array}$ & Fig. 4. The figure describes the \\
\hline \multicolumn{4}{|c|}{ Clinical course } & ent course with oral pentox \\
\hline $\begin{array}{l}\text { Start treatment } \\
\text { with oral } \\
\text { pentoxifylline } \\
(1,200 \mathrm{mg} / \text { day })\end{array}$ & $\begin{array}{l}\text { Oral pentoxifylline } \\
\text { changed to oral } \\
\text { aspirin for } 3 \text { months } \\
(100 \mathrm{mg} / \text { day })\end{array}$ & $\begin{array}{l}\text { Oral aspirin } \\
\text { changed to oral } \\
\text { sulodexide } \\
\text { (750 LSU/day) }\end{array}$ & $\begin{array}{l}\text { Disease } \\
\text { remission was } \\
\text { achieved after } \\
\text { 2-month use of } \\
\text { sulodexide }\end{array}$ & $\begin{array}{l}\text { shows the improvement of the } \\
\text { clinical course with disease remis- } \\
\text { sion after administered sulodexide } \\
\text { for } 2 \text { months. LSU: lipasemic units. }\end{array}$ \\
\hline
\end{tabular}

from recurrent tender, erythematous ulcerative lesions during this treatment, and even though the regimen was changed to daily aspirin (100 mg) for three months, the lesions did not improve. Oral treatment with sulodexide, a heparinoid, replaced that of aspirin. Initial sulodexide treatment dose was 250 lipasemic units, three times daily. Multiple erythematous plaques with ulcerative lesions re-epithelized within the next two months, and the livedo racemosa gradually changed to brownish plaques with center crusts on both legs and feet (Fig. 3). The patient remained in a recurrence-free state three months after sulodexide administration.

\section{DISCUSSION}

Systemic involvement is not a feature of LV; however, many LV patients have atherosclerosis or venous stasis and are often associated with antiphospholipid syndrome ${ }^{2}$. Disease progress was affected by patient general state, including connective tissue diseases, malignant neoplasm, hypercoagulable states, and antithrombin deficiency ${ }^{2}$. Due to its disease progress, various applicable treatments including anticoagulants (warfarin, rivaroxaban), antiplatelet agents (aspirin, pentoxifylline), intravenous immunoglobulin, systemic corticosteroids in conjunction with topical corticosteroids, and intralesional corticosteroid injection have been reported ${ }^{3}$.

Standard guidelines for treatment of LV remain elusive, resulting in various modalities of treatment described in the literature. However, few treatment modalities with superior efficacy in improving LV lesion have been reported. In the report of Weishaupt et al. ${ }^{2}$, treatment response to heparin and rivaroxaban was mostly good/very good, while steroids, nonsteroidal anti-inflammatory drugs, and other modalities showed poor responses. Although the number of involved patients in the trial was small, an obvious difference between heparin or new-oral anticoagulants and other therapies was shown ${ }^{2}$. Sopeña et al. ${ }^{5}$ reported a case of LV accompanying lupus in a patient with recurrent thrombosis, suggesting seronegative antiphospholipid syn- drome that requires anticoagulant treatment. In the report of So et al. ${ }^{6}$, a combination of low-dose aspirin with oral warfarin, an anticoagulant, achieved successful treatment of LV in primary antiphospholipid syndrome. Recently, Franco Marques et al. ${ }^{7}$ reported favorable treatment results of four LV cases using rivaroxaban, suggesting that direct oral anticoagulants (DOACs) could play a role in improving 'recalcitrant' LV, an unresponsive state to oral pentoxifylline and systemic corticosteroid treatment.

Clinical evidence of oral sulodexide has been presented in some previous studies. Treatment with sulodexide in thrombotic diseases such as chronic venous disease and venous ulcers, prevention of myocardial infarction, and alleviation of vascular claudication were all improved in several clinical trials ${ }^{8}$. This is because sulodexide has been shown to improve endothelial function and lipid profiles, has anti-thrombotic and fibrinolytic activity, and inhibits platelet aggregation and leukocyte adhesion ${ }^{8}$. Sulodexide offers minimal changes to coagulation profile and low bleeding risk, indicating it as an alternative treatment for these vascular diseases with minimal adverse effects ${ }^{8}$.

In our case, the patient was diagnosed with LV based on clinical manifestations of tender, erythematous plaques with central crusts and ulcers in conjunction with typical histopathologic findings of LV. The patient also experienced recurrent livedo racemosa and ulcerations during the treatment period with oral pentoxifylline for two years and oral aspirin for three months. However, administration of oral sulodexide instead of the previous regimen successfully improved her lesions. Fig. 4 represents a treatment regimen and disease course. This case suggests that sulodexide, an oral heparinoid, is an effective agent in recalcitrant LV.

Other heparinoid agents such as danaparoid and dermatan sulfate are also known to be useful in prophylaxis and treatment of thromboembolic diseases ${ }^{4}$. To our knowledge, treatment of LV with oral heparinoids such as sulodexide or danaparoid has not been previously reported in the English literature. Due to its chronic disease course with poor quality of life, recalcitrant LV must be treated effec- 
tively. Our case implies an effective method to treat recalcitrant LV with oral heparinoid, which is associated with minimal alterations of blood clotting mechanisms, tests, and bleeding risks in contrast to heparin ${ }^{8}$. Further studies of LV cases treated with oral heparinoid including sulodexide or danaparoid are required to clarify the effectiveness of oral heparinoids in LV patients, and comparative studies between heparinoids and anticoagulants, including warfarin, heparin, and DOACs are necessary.

\section{CONFLICTS OF INTEREST}

The authors have nothing to disclose.

\section{FUNDING SOURCE}

None.

\section{DATA SHARING STATEMENT}

Research data are not shared.

\section{ORCID}

Chang Hwa Song, https://orcid.org/0000-0001-9965-9304 Dong Seok Shin, https://orcid.org/0000-0003-0416-4400 Ju Wang Jang, https://orcid.org/0000-0001-5885-4250 Tae Lim Kim, https://orcid.org/0000-0002-2639-1973 Young Gyun Kim, https://orcid.org/0000-0003-3488-0811 Joung Soo Kim, https://orcid.org/0000-0002-3014-9645
Hyun-Min Seo, https://orcid.org/0000-0002-6897-494X

\section{REFERENCES}

1. Kang $S$, Amagai $M$, Bruckner $A L$, Enk $A H$, Margolis $D$ J, McMichael AJ, et al. Fitzpatrick's dermatology. 9th ed. New York: McGraw-Hill Education, 2019:2532-2533.

2. Weishaupt C, Strölin A, Kahle B, Kreuter A, Schneider SW, Gerss J, et al. Characteristics, risk factors and treatment reality in livedoid vasculopathy- a multicentre analysis. J Eur Acad Dermatol Venereol 2019;33:1784-1791.

3. Micieli $R$, Alavi A. Treatment for livedoid vasculopathy: a systematic review. JAMA Dermatol 2018;154:193-202.

4. Dou H, Song A, Jia S, Zhang L. Heparinoids Danaparoid and Sulodexide as clinically used drugs. Prog Mol Biol Transl Sci 2019;163:55-74.

5. Sopeña B, Pérez-Rodríguez MT, Rivera A, Ortiz-Rey JA, Lamas J, Freire-Dapena MC. Livedoid vasculopathy and recurrent thrombosis in a patient with lupus: seronegative antiphospholipid syndrome? Lupus 2010;19:1340-1343.

6. So BJ, Park JB, Yoo MG, Kim IH, Son SW. Successful treatment of livedoid vasculitis with primary antiphospholipid syndrome by using aspirin and low dose warfarin combination therapy. Ann Dermatol 2015;27:614-615.

7. Franco Marques G, Criado PR, Alves Batista Morita TC, Cajas García MS. The management of livedoid vasculopathy focused on direct oral anticoagulants (DOACs): four case reports successfully treated with rivaroxaban. Int J Dermatol 2018;57:732-741.

8. Coccheri S, Mannello F. Development and use of sulodexide in vascular diseases: implications for treatment. Drug Des Devel Ther 2013;8:49-65. 